\title{
Responses of the perfused liver of neonatal type 2 diabetic rats to gluconeogenic and ammoniogenic substrates
}

\author{
Mirian Carvalho-Martini, Fumie Suzuki-Kemmelmeier, Denise Silva de Oliveira, \\ Jurandir Fernando Comar, Adelar Bracht*
}

Department of Biochemistry, University of Maringá, Maringá, Brazil; *Corresponding Author: adebracht@uol.com.br

Received 23 December 2009; revised 6 February 2010; accepted 8 February 2010.

\begin{abstract}
The responses of livers from rats with type 2 diabetes to alanine (gluconeogenesis and ammonia detoxification) and other gluconeogenic substrates were investigated. The experimental system was the isolated perfused rat liver. Neonatal type 2 diabetes was induced with streptozotocin. Ammoniogenesis from endogenous substrates was $610 \%$ higher in livers from diabetic rats when compared to the control condition. Alanine $(2.5 \mathrm{mM})$ ammoniogenesis was $285 \%$ higher in livers of diabetic rats. Gluconeogenesis from the following substrates was smaller in the liver of diabetic rats: Alanine $(-43.5 \%)$, lactate $(-28.3 \%)$ and glycerol $(-30.5 \%)$. Pyruvate gluconeogenesis was normal. The high rate of ammoniogenesis explains the moderate hyperammonemia of type 2 diabetic rats. The enzymatic machinery of the gluconeogenic pathway of type 2 diabetic rats seems to be adapted to low rates of glucose removal by extrahepatic tissues. A significant contribution of gluconeogenesis to the fasting hyperglycemia can be expected only by short-term up-regulation mechanisms.
\end{abstract}

Keywords: Type 2 Diabetes; Gluconeogenesis; Ammoniogenesis; Alanine; Lactate

\section{INTRODUCTION}

Increased hepatic glucose production is characteristic of type 1 diabetes mellitus [1,2]. Particularly in the fasted state, elevated hepatic gluconeogenesis seems to be the main cause for the hyperglycemic condition in type 1

This work was sponsored by the Conselho Nacional de Desenvolvimento Científico e Tecnológico (CNPq) and Programa Nacional de Núcleos de Excelência (PRONEX, Fundação Araucária-CNPq). diabetes [3]. If the hyperglycemic condition in type 2 diabetes is also at least partly dependent on enhanced gluconeogenesis is not clear. There are reports claiming that this dependence is more accentuated in severely hyperglycemic patients and that it tends to diminish or even vanish in moderately hyperglycemic patients [4]. There are also studies in which no enhanced gluconeogenesis was found in type 2 diabetic patients [5]. It is generally believed that the enhanced gluconeogenesis is caused by an increased efficiency of the gluconeogenic pathway in combination with an augmented mobilization of glucose precursors to the liver [6,7].

Although gluconeogenesis can be measured in vivo using appropriate tracer techniques $[4,8,9]$ it is of interest to reproduce the increased hepatic gluconeogenesis in isolated cell systems because this allows conclusions about its mechanisms. In the isolated perfused rat liver for example, the gluconeogenic activity reflects the enzymatic capacities. These, in turn, reflect the mediumand long-term effects of the circulating hormones on the expression of enzymes and other factors. For type 1 diabetes mellitus, increased gluconeogenesis in isolated hepatocytes or the isolated perfused liver from a variety of substrates has been found [10-15]. When alanine was the substrate, enhanced gluconeogenesis was found in the fasted state, combined with increased rates of urea production and increased rates of alanine incorporation into proteins [11]. These observations with alanine are consistent with the increased rates of mobilization of this amino acid in type 1 diabetes [6]. All these data reveal that short-term regulation operates most probably as a secondary mechanism for the enhanced gluconeogenesis in type 1 diabetes, the medium and long-term expression of key enzymes playing the decisive role [16].

Experiments in which gluconeogenesis was measured in the liver of rats with type 2 diabetes have not been done until now. They are of interest, however, because they will provide the same information about the enzymatic machinery that is already available for type 1 diabetes. The hypothesis that can be formulated is that en- 
hanced gluconeogenesis should be detectable in the isolated rat liver of type 2 diabetic rats in the same way as it was detected in livers from type 1 diabetic animals. Enhanced gluconeogenesis in the isolated organ would be reflecting mainly medium- and long-term effects of the circulating hormones on enzyme expression. With this hypothesis in mind, in the present work experiments were conducted with livers of type 2 diabetic rats. The neonatal streptozotocin-induced rat model of type 2 diabetes mellitus was used. It has been praised as a good model for type 2 diabetes in humans because it presents several of its characteristics [17]. In addition to gluconeogenesis, nitrogen metabolism from alanine was also measured. Evaluation of nitrogen metabolism is of interest because, in addition to hyperglycemia, type 2 diabetic rats also present moderate hyperammonemia [18]. For comparative purposes other gluconeogenic precursors, such as lactate and pyruvate, were also investigated.

\section{MATERIALS AND METHODS}

The liver perfusion apparatus was built in the workshops of the University of Maringá. Enzymes and coenzymes used in the assay procedures and streptozotocin were purchased from Sigma Chemical Co. (St. Louis, USA). All other chemicals were from the best available grade.

Neonatal type 2 diabetes mellitus was induced as previously described $[19,20]$. Male newborn (2 days old) Wistar rats were injected intraperitoneally with streptozotocin $(160 \mathrm{mg} / \mathrm{kg})$ dissolved in citrate buffer. Control rats were injected with citrate buffer. Seven weeks later, diabetes was confirmed by blood glucose levels (8-10 mM), glucose appearance in urine and 24 hours urinary volume (generally 500\% above normal). After seven weeks the mean weights of the control and diabetic rats were $220 \pm 2.8$ and $203.2 \pm 5.2 \mathrm{~g}$, respectively. All animal experiments were done according to the universally accepted standards for animal experimentation.

Rats were fed ad libitum with a standard laboratory diet (Purina ${ }^{\circledR}$ ), but food was withdrawn 24 hours prior to the perfusion experiments. For the surgical procedure, rats were anesthetized by intraperitoneal injection of sodium pentobarbital $(50 \mathrm{mg} / \mathrm{kg})$. Hemoglobin-free, non-recirculating perfusion was undertaken according to the technique described elsewhere [21,22]. After cannulation of the portal and cava veins the liver was positioned in a plexiglass chamber. The hepatic artery was closed (monovascular perfusion) and the bile duct was left open. The flow was maintained constant by a peristaltic pump (Minipuls 3, Gilson, France) and was adjusted to between 30 and $35 \mathrm{ml} \mathrm{min}^{-1}$, depending on the liver weight. The perfusion fluid was Krebs-Henseleitbicarbonate buffer ( $\mathrm{pH} 7.4$ ), saturated with a mixture of oxygen and carbon dioxide (95:5) by means of a mem- brane oxygenator with simultaneous temperature adjustment at $37^{\circ} \mathrm{C}$. The composition of the Krebs-Henseleitbicarbonate buffer is: $115 \mathrm{mM} \mathrm{NaCl}, 25 \mathrm{mM} \mathrm{NaHCO}_{3}$, $5.8 \mathrm{mM} \mathrm{KCl}, 1.2 \mathrm{mM} \mathrm{Na}_{2} \mathrm{SO}_{4}, 1.18 \mathrm{mM} \mathrm{MgCl}_{2}, 1.2 \mathrm{mM}$ $\mathrm{NaH}_{2} \mathrm{PO}_{4}$ and $2.5 \mathrm{mM} \mathrm{CaCl}_{2}$. L-Alanine (2.5 mM), lactate $(2.5 \mathrm{mM})$, pyruvate $(1 \mathrm{mM})$ or glycerol $(2 \mathrm{mM})$ were dissolved in the perfusion fluid. Samples of the effluent perfusion fluid were collected at 4 minute intervals and analyzed for their metabolite content. The following compounds were assayed by means of standard enzymatic procedures [23]: lactate, pyruvate, glucose, urea, ammonia, glutamine and glutamate. The oxygen concentration in the outflowing perfusate was monitored polarographically employing a teflon-shielded platinum electrode adequately positioned in a plexiglass chamber at the exit of the perfusate [22].

Rats after a 24-hours' fast were used because this minimizes interference of endogenous glycogen [24]. As shown by previous work the fasting glycogen levels of control and type 2 diabetic rats are very low when compared to the fed state [18].

Basal rates (absence of substrates) as well as increments caused by substrates (L-alanine, lactate, pyruvate or glycerol) were evaluated. The latter were calculated by subtracting the basal rates (before substrate infusion) from the steady-state rates found at the end of the substrate infusion period. The error parameters presented in graphs and tables are standard errors of the means. Differences between pairs of means were analyzed by means of Student's t test. The $5 \%$ level $(p<0.05)$ was adopted as a criterion of significance.

\section{RESULTS}

Table 1 lists the basal rates of metabolite release of livers from 24-hours fasted rats perfused with substratefree medium. Under such conditions the livers are dependent solely on endogenous sources. The rates were referred to the wet liver weights which were not different in control and diabetic rats, namely $3.31 \pm 0.09$ and 3.53 $\pm 0.13 \mathrm{~g}$ per $100 \mathrm{~g}$ body weight, respectively. As revealed by Table 1 most basal rates were low. This did not occur with oxygen uptake and it should be noted that it was $13.6 \%$ lower in the liver of diabetic rats. Ammonia production, however, was $610 \%$ higher in the diabetic condition. All other parameters were similar in both the control and the diabetic condition.

Figure 1 illustrates the experimental protocol that was employed in the present study as well as the time course of the changes in three selected parameters. Sampling of the effluent perfusate for metabolite determination was always initiated after oxygen uptake stabilization (zero time). Alanine infusion was initiated at 12 minutes in the time scale of Figure 1. The time courses of the changes 


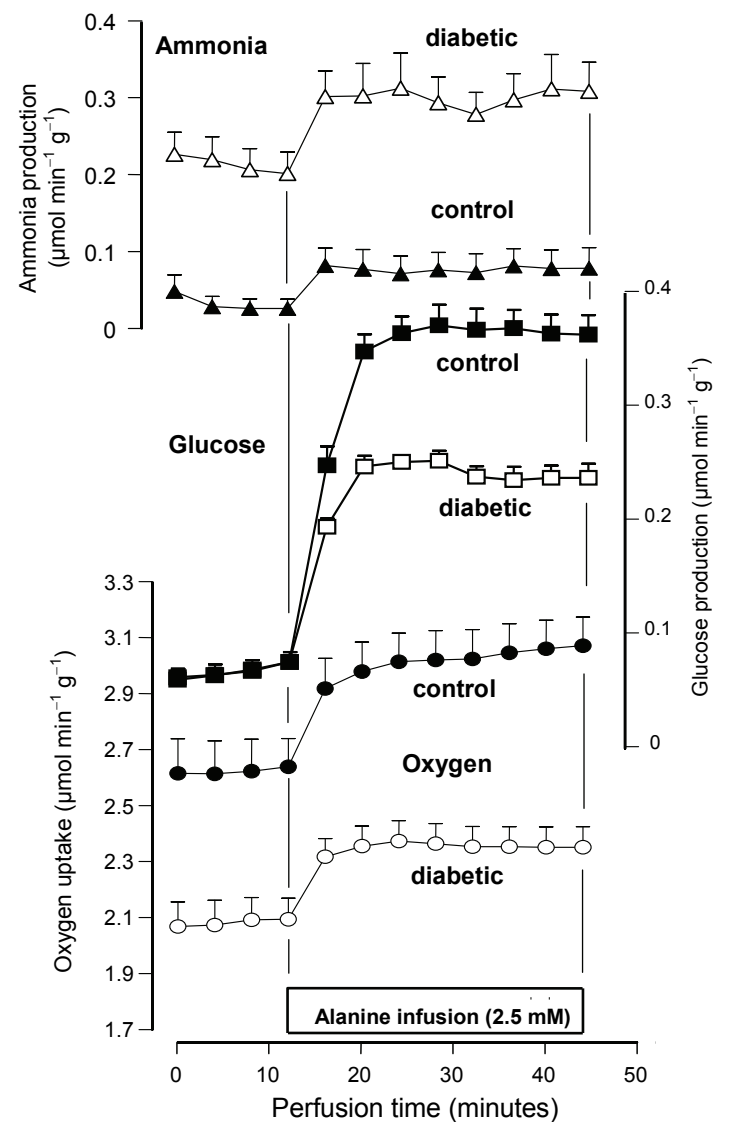

Figure 1. Time course of changes in oxygen uptake, glucose production and ammonia production in livers from fasted control and type 2 diabetic rats. Livers were perfused as described in Material and Methods. Alanine was infused as indicated by the horizontal bar. Results obtained with livers of control rats were represented by full symbols and those of diabetic rats with empty symbols. Data are means \pm SEM of 9 (control) and 5 (diabetic) liver perfusion experiments.

in ammonia and glucose production and oxygen uptake were represented. The basal values of ammonia production, oxygen uptake and glucose release correspond to those ones listed in Table 1. The introduction of alanine caused increases in all parameters which tended to new steady-states during the following 30 minutes. Differences between the control and diabetic conditions were not only maintained but even accentuated because glucose production from alanine was smaller in the diabetic condition.

Figure 1 reveals that new steady-state levels were reached in consequence of alanine infusion. The steadystate rates and the increments caused by alanine infusion were evaluated and listed in Table 2. In addition to the three parameters that were represented in Figure 1, the rates of urea, lactate, pyruvate, glutamate and glutamine production were also shown in Table 2. Alanine infusion caused increases in all parameters and not only in those ones shown in Figure 1. The increment in ammonia production caused by alanine was higher in the diabetic condition. The increments in oxygen uptake, urea, glucose and glutamine productions, however, were smaller in the diabetic condition. Gluconeogenesis from alanine was, thus, smaller in the liver of diabetic rats $(-43.5 \%)$. The total nitrogen flux generated by alanine infusion can be approximated by the sum of ammonia production $+(2$ $\times$ urea production $)+(2 \times$ glutamine production $)+$ glutamate production, after subtracting the basal rates (before alanine infusion). In livers of control rats this calculation yielded a total nitrogen flux of $1.18 \mu \mathrm{mol} \mathrm{min}^{-1}$ $\mathrm{g}^{-1}$; in the diabetic condition the corresponding value was $0.88 \mu \mathrm{mol} \mathrm{min} \mathrm{m}^{-1} \mathrm{~g}^{-1}$, the difference amounting to $25.6 \%$.

Glucose production from lactate, pyruvate and glycerol was investigated by using essentially the same experimental protocol illustrated for alanine in Figure 1. The results are summarized in Tables 3 to $\mathbf{5}$. Table 3 shows that gluconeogenesis from $2.5 \mathrm{mM}$ lactate was $28.3 \%$ smaller in livers from diabetic rats. The final oxygen uptake was also considerably smaller in the diabetic condition. Pyruvate production from lactate tended to be more pronounced in the diabetic condition, but there was no statistical significance at the $5 \%$ level. For pyruvate metabolism, on the other hand, no significant differences were found in glucose production, oxygen uptake and lactate production, as revealed by Table 4 . There was a strong tendency, however, for higher values of glucose production in the diabetic condition ( $p=$ 0.061 ). Glucose production from glycerol however, was $30.5 \%$ smaller in the diabetic condition as revealed by Table 5. Lactate production from glycerol, however, was not statistically different. Pyruvate production from glycerol was negligibly small.

\section{DISCUSSIONS}

The results reveal that the metabolism of livers from neonatal type 2 diabetic rats presents a few differences when compared to livers from normal and also type 1 diabetic rats. These differences encompass both ammonia detoxification and carbohydrate metabolism. The liver of type 1 diabetic rats has been reported to present considerably higher rates of urea production [11]. This makes a clear contrast with the liver of type 2 diabetic rats where ureogenesis was found to be close to normal (Tables 1 and 2). Consistently, the plasma urea level of type 1 diabetic rats is very high, but normal in type 2 diabetic rats [2-18]. The perfused liver of type 2 diabetic rats, on the other hand, presented higher rates of ammonia production under both conditions examined in the present work, i.e., during substrate-free perfusion and during alanine infusion (Tables $\mathbf{1}$ and 2). In relative terms the difference was more pronounced in the 
Table 1. Basal rates of metabolites release and oxygen uptake in perfused livers from control and type 2 diabetic rats. Significant differences are indicated by an asterisk $(\mathrm{p}<0.05)$. The results come from experiments in which various substrates were infused at 12 minutes perfusion time as illustrated by Figure 1.

\begin{tabular}{ccc}
\hline Metabolic flux & Control & Diabetic \\
\cline { 2 - 3 } & \multicolumn{1}{c}{$\mu \operatorname{col}_{\min ^{-1}(\mathrm{~g} \text { liver wet weight })^{-1}}$} & $0.206 \pm 0.028^{*}(\mathrm{n}=5)$ \\
\hline Ammonia production & $0.029 \pm 0.012(\mathrm{n}=9)$ & $0.171 \pm 0.003(\mathrm{n}=5)$ \\
Urea production & $0.140 \pm 0.016(\mathrm{n}=9)$ & $0.062 \pm 0.006(\mathrm{n}=5)$ \\
Glutamine production & $0.064 \pm 0.007(\mathrm{n}=9)$ & $0.031 \pm 0.007(\mathrm{n}=5)$ \\
Glutamate production & $0.034 \pm 003(\mathrm{n}=9)$ & $2.135 \pm 0.063 *(\mathrm{n}=17)$ \\
Oxygen uptake & $2.470 \pm 0.065(\mathrm{n}=18)$ & $0.064 \pm 0.006(\mathrm{n}=16)$ \\
Glucose production & $0.080 \pm 0.010(\mathrm{n}=17)$ & $0.051 \pm 0.014(\mathrm{n}=11)$ \\
Lactate production & $0.052 \pm 0.007(\mathrm{n}=13)$ & $0.009 \pm 0.006(\mathrm{n}=13)$ \\
Pyruvate production & $0.007 \pm 0.002(\mathrm{n}=13)$ &
\end{tabular}

Table 2. Metabolic fluxes in livers from control and type 2 diabetic rats caused by alanine infusion (2.5 mM). The data were obtained from experiments in which alanine was infused during 30 minutes. Asterisks $(*)$ and crosses $(\dagger)$ indicate values in the diabetic condition that are statistically different from the corresponding control values according to Student's t test $(p<0.05)$

\begin{tabular}{|c|c|c|c|c|}
\hline \multirow{3}{*}{ Parameter } & \multicolumn{2}{|c|}{ Control $(n=9)$} & \multicolumn{2}{|c|}{ Diabetic $(n=5)$} \\
\hline & \multicolumn{4}{|c|}{$\mu \mathrm{mol} \min ^{-1}(\mathrm{~g} \text { liver wet weight })^{-1}$} \\
\hline & $\begin{array}{l}\text { Rate in the presence of } \\
\text { alanine }\end{array}$ & $\begin{array}{c}\text { Increment caused by } \\
\text { alanine }\end{array}$ & $\begin{array}{c}\text { Rate in the presence of } \\
\text { alanine }\end{array}$ & $\begin{array}{c}\text { Increment caused by } \\
\text { alanine }\end{array}$ \\
\hline Ammonia production & $0.081 \pm 0.025$ & $0.052 \pm 0.016$ & $0.312 \pm 0.041 \dagger$ & $0.106 \pm 0.013^{*}$ \\
\hline Urea production & $0.499 \pm 0.030$ & $0.359 \pm 0.021$ & $0.416 \pm 0.019$ & $0.245 \pm 0.011 *$ \\
\hline Glutamine production & $0.255 \pm 0.015$ & $0.191 \pm 0.011$ & $0.191 \pm 0.008 \dagger$ & $0.129 \pm 0.005^{*}$ \\
\hline Glutamate production & $0.060 \pm 0.005$ & $0.026 \pm 0.002$ & $0.053 \pm 0.010$ & $0.022 \pm 0.004$ \\
\hline Oxygen uptake & $3.064 \pm 0.102$ & $0.434 \pm 0.048$ & $2.349 \pm 0.073 \dagger$ & $0.258 \pm 0.026^{*}$ \\
\hline Glucose production & $0.364 \pm 0.017$ & $0.292 \pm 0.014$ & $0.238 \pm 0.011 \dagger$ & $0.165 \pm 0.013^{*}$ \\
\hline Lactate production & $0.307 \pm 0.019$ & $0.255 \pm 0.015$ & $0.285 \pm 0.024$ & $0.234 \pm 0.019$ \\
\hline Pyruvate production & $0.122 \pm 0.028$ & $0.115 \pm 0.026$ & $0.160 \pm 0.018$ & $0.151 \pm 0.017$ \\
\hline
\end{tabular}

Table 3. Metabolic fluxes in livers from control and type 2 diabetic rats caused by lactate infusion $(2.5 \mathrm{mM})$. The data were obtained from experiments in which lactate was infused during 30 minutes. Asterisks $(*)$ and crosses $(\dagger)$ indicate values in the diabetic condition that are statistically different from the corresponding control values according to Student's $\mathrm{t}$ test $(p<0.05)$.

\begin{tabular}{|c|c|c|c|c|}
\hline \multirow{3}{*}{ Parameter } & \multicolumn{2}{|c|}{ Control $(n=4)$} & \multicolumn{2}{|c|}{ Diabetic $(n=5)$} \\
\hline & \multicolumn{4}{|c|}{ umol $\min ^{-1}(\mathrm{~g} \text { liver wet weight })^{-1}$} \\
\hline & $\begin{array}{c}\text { Rate in the presence of } \\
\text { lactate }\end{array}$ & $\begin{array}{c}\text { Increment caused by } \\
\text { lactate }\end{array}$ & $\begin{array}{c}\text { Rate in the presence of } \\
\text { lactate }\end{array}$ & $\begin{array}{c}\text { Increment caused by } \\
\text { lactate }\end{array}$ \\
\hline Oxygen uptake & $3.195 \pm 0.228$ & $0.629 \pm 0.042$ & $2.631 \pm 0.070 \dagger$ & $0.531 \pm 0.029$ \\
\hline Glucose production & $0.998 \pm 0.119$ & $0.922 \pm 0.118$ & $0.737 \pm 0.021 \dagger$ & $0.661 \pm 0.018^{*}$ \\
\hline Pyruvate production & $0.200 \pm 0.101$ & $0.182 \pm 0.100$ & $0.334 \pm 0.097$ & $0.324 \pm 0.101$ \\
\hline
\end{tabular}


Table 4. Metabolic fluxes in livers from control and type 2 diabetic rats caused by pyruvate infusion (1.0 mM). The data were obtained from experiments in which pyruvate was infused during 20 minutes.

\begin{tabular}{|c|c|c|c|c|}
\hline \multirow{3}{*}{ Parameter } & \multicolumn{2}{|c|}{ Control $(n=4)$} & \multicolumn{2}{|c|}{ Diabetic $(n=3)$} \\
\hline & \multicolumn{4}{|c|}{$\mu \mathrm{mol} \mathrm{min}^{-1}(\mathrm{~g} \text { liver wet weight })^{-1}$} \\
\hline & $\begin{array}{c}\text { Rate in the presence of } \\
\text { pyruvate }\end{array}$ & $\begin{array}{c}\text { Increment caused by } \\
\text { pyruvate }\end{array}$ & $\begin{array}{c}\text { Rate in the presence of } \\
\text { pyruvate }\end{array}$ & $\begin{array}{c}\text { Increment caused by } \\
\text { pyruvate }\end{array}$ \\
\hline Oxygen uptake & $2.657 \pm 0.101$ & $0.361 \pm 0.045$ & $2.658 \pm 0.014$ & $0.434 \pm 0.059$ \\
\hline Glucose production & $0.399 \pm 0.049$ & $0.340 \pm 0.042$ & $0.515 \pm 0.013$ & $0.463 \pm 0.014$ \\
\hline Lactate production & $1.143 \pm 0.063$ & $1.103 \pm 0.059$ & $1.232 \pm 0.047$ & $1.158 \pm 0.022$ \\
\hline
\end{tabular}

Table 5. Metabolic fluxes in livers from control and type 2 diabetic rats caused by glycerol infusion (2.0 mM). The data were obtained from experiments in which glycerol was infused during 20 minutes. Asterisks $(*)$ and crosses $(\dagger)$ indicate values in the diabetic condition that are statistically different from the corresponding control values according to Student's t test $(p<0.05)$.

\begin{tabular}{|c|c|c|c|c|}
\hline \multirow{3}{*}{ Parameter } & \multicolumn{2}{|c|}{ Control $(n=4)$} & \multicolumn{2}{|c|}{ Diabetic $(n=4)$} \\
\hline & \multicolumn{4}{|c|}{$\mu \mathrm{mol} \min ^{-1}(\mathrm{~g} \text { liver wet weight })^{-1}$} \\
\hline & $\begin{array}{c}\text { Rate in the presence of } \\
\text { glycerol }\end{array}$ & $\begin{array}{c}\text { Increment caused by } \\
\text { glycerol }\end{array}$ & $\begin{array}{c}\text { Rate in the presence of } \\
\text { glycerol }\end{array}$ & $\begin{array}{c}\text { Increment caused by } \\
\text { glycerol }\end{array}$ \\
\hline Oxygen uptake & $2.696 \pm 0.126$ & $0.173 \pm 0.066$ & $2.077 \pm 0.078 \dagger$ & $0.061 \pm 0.020$ \\
\hline Glucose production & $0.609 \pm 0.049$ & $0.518 \pm 0.051$ & $0.423 \pm 0.036 \dagger$ & $0.362 \pm 0.035^{*}$ \\
\hline Lactate production & $0.140 \pm 0.049$ & $0.091 \pm 0.009$ & $0.103 \pm 0.036$ & $0.056 \pm 0.016$ \\
\hline
\end{tabular}

absence of alanine, a condition where ammonia comes solely from endogenous catabolic reactions. Even the second route of ammonia detoxification, namely glutamine production [25], seems to be impaired in the liver of type 2 diabetic rats, as can be judged from its lower rates in the presence of alanine (Table 2). The higher rates of ammonia production can be indicating that nitrogen catabolism in livers of type 2 diabetic rats surpasses the capacity of the urea cycle when this route depends solely on endogenous substrates and on endogenous substrates plus alanine. In principle this conclusion receives support from the higher plasma ammonia levels in type 2 diabetic rats [18]. It must be remarked, however, that the difference in the plasma ammonia levels between diabetic and control rats, as reported previously [18], is relatively small $(+28 \%)$ when compared to the difference in ammoniogenesis $(+285 \%$ in the presence of alanine). Extrapolation to the in vivo conditions is always subject to error, but it principle one would expect a more severe hyperammonemia in type 2 diabetic rats. Possibly there is some in vivo mechanism or mechanisms that avoid the development of severe hyperammonemia. One of these mechanisms could be higher rates of renal excretion. Alternatively, there could be a more efficient transformation of ammonia into urea and glutamine in vivo than that one found in the isolated perfused liver due to the presence of factors capable of stimulating ureogenesis.
With reference to the main hypothesis of the present work, it is apparent from the results of the present study that hepatic gluconeogenesis in neonatal type 2 diabetic rats is lower than that in non-diabetic rats, at least with the relevant precursors lactate, alanine and glycerol. This can also be interpreted as meaning, in principle at least, that the enzymatic machinery of the liver from neonatal type 2 diabetic rats is not adapted to higher rates of gluconeogenesis but much more to the lower rates of glucose uptake by peripheral tissues [26]. No significant difference was found when pyruvate was the substrate. There was a tendency toward higher rates of glucose synthesis in the diabetic condition without statistical significance, however, possibly due to the small number of rats used in these experiments. However, pyruvate is the only substrate used in the present work that induces, in the once-through perfused liver at least, an oxidizing state in the liver cells when it is present alone (i.e., very low NADH/NAD ratios) [27]. This is a situation that does not normally occur in vivo where the pyruvate concentrations are normally very low and the lactate to pyruvate ratios high [27]. These results with livers of type 2 diabetic rats are in sharp contrast with those obtained with the liver of type 1 diabetic rats, where increased gluconeogenesis with virtually all substrates was observed [10-15]. Although the rates of oxygen uptake were always lower in the liver of diabetic rats even in the presence of gluconeogenic substrates, it is unlikely that ATP availability could be limiting glucose synthesis. 
As shown previously, the ATP content of the hepatic tissue of type 2 diabetic rats under the same conditions as those used in the present work (24-hours fast) is even higher than that of normal rats [18]. Furthermore, there was a clear correlation between the increments in oxygen uptake caused by lactate, alanine and pyruvate and the gluconeogenic activity. This reinforces the general notion that gluconeogenesis controls the extra oxygen uptake and not the contrary.

It should be stressed with reference to the contribution of gluconeogenesis to the fasting hyperglycemia in animals and patients with type 2 diabetes that conflicting results have been reported. There are studies proposing a significant, though relatively small, contribution of gluconeogenesis to the fasting hyperglycemia $[4,6,8]$ while others claim that the contribution is not significant $[6,26]$. Our results thus agree much more with those studies in which no enhanced gluconeogenesis was found in type 2 diabetic patients.

Extrapolations of the observations of the present work to the in vivo conditions or to different species (mice, humans) must always be done carefully. Even so, it should be stressed that in vivo lower rates of gluconeogenesis in humans or animals bearing type 2 diabetes have never been reported. Consequently it seems worth to discuss the possible factors that could lead to an at least normal or slightly above normal in vivo gluconeogenesis in spite of impaired enzymatic machinery. If one assumes that the enzymatic machinery is the result of long- or even medium-term regulation, efficient mechanisms of short-term up-regulation must be operative in type 2 diabetes, at least in the rat. There are several possibilities to be considered: 1) different concentrations of hormones able to stimulate gluconeogenesis; 2) higher substrate concentrations in the diabetic condition; 3) increased plasma concentrations of free fatty acid, which are known to estimulate gluconeogenesis [24-28]. With reference to the hormonal factors, it is known that glucagon, in addition to its medium- and long-term effects [16] can also promote short-term up-regulation of gluconeogenesis [29,30]. Insulin, in contrast, does not exert short-term effects in the liver [10,11]. Elevated glucagon levels have been found in type 2 diabetic humans [9-31] and in neonatal streptozotocin type 2 diabetic rats at least during certain stages after streptozotocin injection [17]. Consequently a short-term up-regulation by glucagon must be considered as a real possibility. It must be mentioned, however, that the stimulatory effect of glucagon on gluconeogenesis is relatively modest unless the cytosolic $\mathrm{NADH} / \mathrm{NAD}^{+}$ratio is very high $[29,30]$. Concerning the possible contribution of increased substrate concentrations one cannot expect a significant contribution from lactate. The latter is by far the most important gluconeogenic substrate, but its normal concentration in blood (around $2 \mathrm{mM}$ ) is already saturating for glu- coneogenesis $[28,32]$ so that increments would not enhance glucose synthesis. Some positive effect favouring gluconeogenesis in the diabetic state could be expected, however, by a shift in the redox potential of the cytosolic NAD-NADH couple towards a more oxidized state (lower NADH/NAD ${ }^{+}$ratios). This would have the consequence of increasing the pyruvate concentration by virtue of the near-equilibrium of the lactate dehydrogenase reaction [27]. This positive effect is to be expected from the observation that when pyruvate was the sole substrate, a condition which means a strong oxidizing state for the cytosolic NAD-NADH couple [27], the difference between gluconeogenesis in the diabetic and the normal state was practically abolished. In a specific study with type 2 diabetic patients [31], plasma glycerol was increased by a factor of 1.46 and glycerol gluconeogenesis was increased more than twofold. From the glycerol concentration increase one would expect maximally a 1.46-fold increase in gluconeogenesis from this substrate. This disproportion, two-fold versus 1.46fold, can be regarded as an indication that another factor or factors are contributing to the enhanced gluconeogenesis. One of these factors could be the more elevated glucagon concentration, as already mentioned. However, the more elevated fatty acid concentrations, which seem to be a frequent phenomenon in type 2 diabetes [4,31], could be equally contributing as stimulatory effectors.

In conclusion, the enzymatic machinery of the gluconeogenic pathway of neonatal type 2 diabetic rats seems to be adapted to low rates of glucose removal by extrahepatic tissues rather than to enhanced glucose production. Gluconeogenesis at rates high enough to contribute significantly to the fasting hyperglycemia can be generated only by short-term up-regulation which could, in principle, be produced by high glucagon, glycerol and fatty acids concentrations.

\section{ACKNOWLEDGEMENTS}

The authors wish to thank Dr. Ciomar Bersani Amado for supplying the diabetic rats.

\section{REFERENCES}

[1] Kraus-Friedmann, N. (1984) Hormonal regulation of hepatic gluconeogenesis. Physiology Reviews, 64, 170259.

[2] Pilks, S.J. and Granner, D.K. (1992). Molecular physiology of the regulation of hepatic gluconeogenesis and glycolysis. Annual Review of Physiology, 54, 885-909.

[3] Petersen, K.F., Price, T.B. and Bergeron, R. (1993) Regulation of net hepatic glycogenolysis and gluconeogenesis during exercise: Impact of type 1 diabetes. Journal of Clinical Endocrinology and Metabolism, 89(9), 46564664.

[4] Boden, G., Chen, X. and Stein, T.P. (2001) Gluconeo- 
genesis in moderately and severely hyperglycemic patients with type 2 diabetes mellitus. American Journal of Physiology, Endocrinology and Metabolism, 280(1), E23-E30.

[5] Diraison, F., Large, V., Brunengraber, H. and Beylot, M. (1998) Non-invasive tracing of liver intermediary metabolism in normal subjects and in moderately hyperglycaemic NIDDM subjects: Evidence against increased gluconeogenesis and hepatic fatty acid oxidation in NIDDM. Diabetologia, 41, 212-220.

[6] Andrikopoulos, S. and Proietto, J. (1995) The biochemical basis of increased hepatic glucose production in a mouse model of type 2 (non-insulin-dependent) diabetes mellitus. Diabetologia, 38, 1389-1396.

[7] Puhakainen, I., Koivisto, V.A. and Yki-Jarvinen, H. (1992) Lipolysis and gluconeogenesis from glycerol are increased in patients with noninsulin-dependent diabetes mellitus. Journal of Clinical Endocrinology and Metabolism, 75, 789-794.

[8] Magnusson, I., Rothman, D.L., Katz, L.D., Shulman, R.G. and Shulman, G.I. (1992) Increased rate of gluconeogenesis in type II diabetes mellitus. Journal of Clinical Investigation, 90(4), 1323-1327.

[9] Basu, R., Schwenk, W.F. and Rizza, R.A. (2004) Both fasting glucose production and disappearance are abnormal in people with "mild" and "severe" type 2 diabetes. American Journal of Physiology-Endocrinology and Metabolism, 287(1), E55-E62.

[10] Söling, H.D., Koschel, R., Dragert, W., Kneer, P. and Creutzfeldt, W. (1966) The effect of insulin on the metabolism of isolated perfused livers of normal and alloxan-diabetic rats. I. The metabolism of isolated perfused livers in normal and alloxan-diabetic rats under various experimental conditions. Diabetologia, 2(1), 20- 31.

[11] Rudorff, K.H., Albrecht, G. and Staib, W. (1970) Über den Einflu $\beta$ von Insulin und Proinsulin auf die Gluconeogenese aus alanin in der isoliert perfundierten leber normaler und alloxandiabetischer ratten. Hoppe-Seyler's Zeitschrift für Physiologische Chemie, 351, 975-982.

[12] Cook, D.E. (1978) The effects of phenformin in normal vs. diabetic isolated perfused rat liver. Research Communications in Chemical Pathology and Pharmacology, 22, 119-134.

[13] Wagle, S.R., Ingebretsen, W.R. and Sampson, L. (1975) Studies on gluconeogenesis and stimulation of glycogen and protein synthesis in isolated hepatocytes in alloxan diabetic, normal fed and fasted animals. Acta Diabetologica Latina, 12, 185-198.

[14] Lombardo, Y.B., Hron, W.T. and Menahan, L.A. (1978) Effect of insulin in vitro on the isolated, perfused alloxan-diabetic rat liver. Diabetologia, 14(1), 47-51.

[15] Akimoto, L.S., Pedrinho, S.R., Lopes, G. and Bazotte, R.B. (2000) Rates of gluconeogenesis in perfused liver of alloxan-diabetic fed rats. Research Communications in Molecular Pathology and Pharmacology, 107(1-2), 6577.

[16] Barthel, A. and Schmoll, D. (2003) Novel concepts in insulin regulation of hepatic gluconeogenesis. American Journal of Physiology, Endocrinology and Metabolism, 285(4), E685-E692.

[17] Arulmozhi, D.K., Veeranjaneyulu, A. and Bodhankar,
S.L. (2004) Neonatal streptozotocin-induced rat model of type 2 diabetes mellitus: A glance. Indian Journal of Pharmacology, 36(4), 217-221.

[18] Oliveira, D.S., Bersani-Amado, C.A., Martini, M.C., Suzuki-Kemmelmeier, F. and Bracht, A. (2007) Glycogen levels and energy status of the liver of fasting rats with diabetes types 1 and 2. Brazilian Archives of Biology and Technology, 50(5), 785-791.

[19] Portha, B., Levacher, C., Picon, L. and Rosselin, G. (1974) Diabetogenic effect of streptozotocin in the rat during the perinatal period. Diabetes, 23(11), 889-895.

[20] Cuman, R.K.N., Bersani-Amado, C. and Fortes, Z.B. (2001) Influence of type 2 diabetes upon the inflammatory response in rats. Inflammation, 50(9), 460-465.

[21] Scholz, R. and Bücher, T. (1965) Hemoglobin-free perfusion of rat liver. In: Changce, B., Estabrook, W. and Williamson, J.R., Eds., Control of Energy Metabolism, Academic Press, New York, 393-414.

[22] Bracht, A., Ishii-Iwamoto, E.L. and Kelmer-Bracht, A.M. (2003) O estudo do metabolismo no fígado em perfusão. In: Bracht, A. and Ishii-Iwamoto, E.L. Eds., Métodos de Laboratório em Bioquímica, Editora Manole, São Paulo, 275-289.

[23] Bergmeyer, H.U. (1974) Methods of Enzymatic Analysis, Verlag Chemie-Academic Press, Weinheim-London.

[24] Bazotte, R.B., Constantin, J., Hell, N.S. and Bracht, A. (1990) Hepatic metabolism of meal-fed rats: Studies in vivo and in the isolated perfused liver. Physiology and Behavior, 48(2), 247-253.

[25] Häussinger, D., Gerok, W. and Sies, S. (1983) Regulation of flux through glutaminase and glutamine synthetase in isolated perfused rat liver. Biochimica et Biophysica Acta, 755(2), 272-278.

[26] Beck-Nielsen, H., Hother-Nielsen, O. and Staehr, P. (2002) Is hepatic glucose production increased in type 2 diabetes mellitus? Current Diabetes Reports, 2, 231-236.

[27] Sies, H. (1982) Nicotinamide nucleotide compartmentation. In: Sies, H., Ed., Metabolic Compartmentation. Academic Press, New York, 205-231.

[28] Veiga, R.P., Silva, M.H., Teodoro, G.R., Yamamoto, N.S., Constantin, J. and Bracht, A. (2008) Metabolic fluxes in the liver of rats bearing the walker 256 tumor: Influence of the circulating levels of substrates and fatty acids. Cell Biochemistry and Function, 26(1), 51-63.

[29] Constantin, J., Ishii-Iwamoto, E.L., Suzuki Kemmelmeie, F. and Bracht, A. (1994) Zonation of the action of glucagon on gluconeogenesis studied in the bivascularly perfused rat liver. FEBS Letters, 352(1), 24-26.

[30] Marques da Silva, A.C., D’Ávila, R.B., Ferrari, A.G., Kelmer-Bracht, A.M., Constantin, J. and Bracht, A. (1997) $\mathrm{Ca}^{2+}$-dependence of gluconeogenesis stimulation by glucagon at different cytosolic $\mathrm{NAD}^{+}$-NADH redox potentials. Brazilian Journal of Medical and Biological Research, 30(7), 827-836.

[31] Nurjhan, N., Conoli, A. and Gerich, J. (1992) Increased lipolysis and its consequences on gluconeogenesis in noninsulin-dependent diabetes mellitus. Journal of Clinical Investigation, 89(1), 169-175.

[32] Argilés, J.M. and López-Soriano, F.J. (1991) The energy state of tumorbearing rats. Journal of Biological Chemistry, 266, 2978-2982. 